\title{
Systematic research of e-learning platforms for solving challenges faced by Indian engineering students
}

Systematic research of e-learning platforms
Received 22 September 2020 Revised 11 October 2020 20 October 2020 26 October 2020 9 November 2020

Accepted 11 November 2020

\begin{abstract}
Purpose - As educational institutes began to address the challenges posed by COVID-19, e-learning came to the foreground as the best bet left. This study is in quest of revealing engineering student's perceptions of the available e-learning platforms, thus surfacing the underlying bottlenecks. Further, it aims at providing solutions that would help enhance the e-learning experience not only in pandemic times but also in the long run. Design/methodology/approach - This holistic research begins with a comprehensive comparative study about the available e-learning platforms, followed by a primary data analysis through an online survey of 364 engineering students from various colleges and branches. The collected data was analyzed to detect bottlenecks in online learning and suggestions are given for solving some challenges.

Findings - On a five-point Likert scale, the available e-learning platforms garnered ratings ranging from 2.81 to 3.46. Google meet was the most preferred platform. However, with a net promoter score (NPS) of 30.36, Microsoft Teams emerged as the most satisfying platform. Technical shortcomings clubbed with psychological and biological factors were found to be taking a toll on e-learning.

Research limitations/implications - This innovative research is based on the perceptions of engineering students hailing majorly from Indian cities, and hence, it may be having educational stream bias and geographical bias. The research could be further extended to cover rural areas and global trends in e-learning. Originality/value - The research offers a thorough analysis of e-learning platforms, as seen through the lens of engineering students. Furthermore, the analysis does not constrain itself to the technicalities and thus proves to be an all-encompassing one, potent enough to surface critical issues marring the e-learning experience.
\end{abstract}

Keywords Online teaching, e-learning platform, Engineering education, Open and Distance education

Paper type Research paper

\section{Introduction}

Acting as an interface between science and society, engineering surpasses the boundaries of knowledge, analysis and practices the sublime art of organizing forces of technological change. An effective transfer of engineering education stands on the pillars of remembering, understanding, applying, analyzing, evaluating and creating (Barak, 2013).

With the advent of neoliberal market policies, the private sector in engineering and technical education has shifted the focus from philanthropy to profit thereby resulting in a poor quality of education and a mere 25\% employability rate (Choudhury, 2019; Gambhir et al., 2016). To add to the existing troubles, COVID-19 has caused education to blow up in the air like an unprecedented display of fireworks. Education systems have no choice but to

(C) Shivangi Viral Thakker, Jayesh Parab and Shubhankar Kaisare. Published in the Asian Association of Open Universities Journal. Published by Emerald Publishing Limited. This article is published under the Creative Commons Attribution (CC BY 4.0) licence. Anyone may reproduce, distribute, translate and create derivative works of this article (for both commercial and non-commercial purposes), subject to full attribution to the original publication and authors. The full terms of this licence may be seen at http:// creativecommons.org/licences/by/4.0/legalcode

The authors are grateful to all the students of various engineering colleges for responding to the survey and using the online platforms for a month as a prerequisite for the survey.

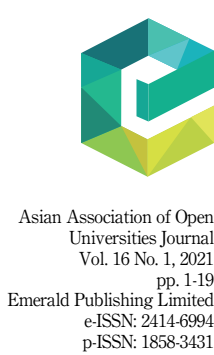

DOI 10.1108/AAOUJ 
AAOUJ 16,1

accept the digital checkmate imposed, ranging from major shutdowns of classroom teaching to spontaneous virtualization (Xiao, 2018). Lack of access to remote learning tools and materials has pushed an alarming number of students not just out of colleges but also out of the system (Azorín, 2020).

COVID-19 has left the post-pandemic education system with two possibilities: a return to traditional education or a transformation towards enhanced education. The key to transformational change will be for systems to focus on their professional capital and find ways to develop teachers' knowledge and skills, support effective collaborative networks that include parents (McPhee and Söderström, 2012). Including educators in the decision- making and communication process ensures easy transformation (Hollweck and Doucet, 2020).

This paper identifies the current perception of available e-learning platforms among engineering students. A comprehensive internal study followed by a thorough analysis helps detect the underlying problems. Further, the paper proposes solutions for these problems to ensure that the transition to e-learning is a smooth endeavor.

\section{Literature review}

There are recent studies on the demands and needs of engineering education and the exact process of distance learning in the Internet environment. The current effect of the COVID-19 pandemic on the education sector globally and countrywide is studied by few researchers recently. There is a dire need to search for online learning tools available currently and their impact on future e-learning and classroom learning aspects (Hillier, 2018). The following sub-sections give a detailed literature review done on Engineering education requirements, the effect of the pandemic on the education system, various e-learning platforms, and a comparison of online survey methods.

\subsection{Engineering education}

Fuentes-Del-Burgo and Navarro-Astor (2016) explained in brief how the concepts of "episteme," "techne" and "phronesis" given by Aristotle are associated with engineering education. Though mainly concerned with Spanish building engineers, it almost gives a worldwide perspective on how various educational factors play an important role in building good engineers and various suggestions to improve them. Barak (2013) discusses how the United States has implemented the three principles of K-12 education and how it can be utilized in other countries to have an overall development of engineering students. The difference between technology and engineering; integration of Bloom's Taxonomy and K-12 education; and the importance of cognitive education on the improvement of engineering students have also been explained.

Choudhury (2019), surveyed 1178 undergraduate engineering students in Delhi to understand student's perceptions of various criteria of teaching methods used, skills acquired by the students, and involvement of students. This does provide a brief overview of the current situation of engineering education in India and how the current teaching methods can be improved. Upadhayay and Vrat (2017), have analyzed the growth of India's technical education from the system's dynamic perspective followed by a comparison with the Gartner Hype cycle. The concept of the Boomerang effect has been introduced in this paper to compare it with the current movement of Indian technical education along with concerns over the quality of technical education currently in India. Gambhir et al. (2016) echo the same concerns and have developed a methodology to build a quality model for the integration of various factors in a technical institute.

\subsection{COVID-19 pandemic's effect on education}

UNESCO report (2020) gives some interesting numbers on how much the pandemic has affected the education system globally. The study indicates that $60.9 \%$ of the enrolled 
student population has been affected with over 1 billion student learners affected and 107 nationwide closures (as of July 2020). The study shows that this pandemic has crippled the education system all over the world further emphasizing the need for new measures to be taken to handle this inopportune time.

Carteret al. (2020) have discussed the effect of COVID-19 on classroom education and how elearning would need to come to the forefront. The concept of self-regulated learning has been introduced along with its components and ways to integrate it with online learning. Hollweck and Doucet (2020) have also discussed the effects of COVID-19 on education, but they have created an interesting analogy with supernova. They have compared COVID-19 with a supernova in terms that after a supernova event everything changes for the better and the status quo are broken which was unraveling before. Similarly, the paper takes this pandemic as an opportunity to disrupt the status quo and build the education system in a much better way.

Further, Fullan (2020) reiterates that evolution could have wonderful things in store for us - but only if we do our part to shape it and thus hints to take this pandemic positively. Izumi et al. (2020) have similarly gone about discussing the issue of COVID-19 on the transition from classroom learning to online learning and the financial strains of the same. They have surveyed to understand the preparedness for such a transition and the available infrastructure. This has given great insight into the current capacity of the world to transform itself from classroom teaching to online learning.

Lall and Singh (2020) have discussed the impact of COVID-19 on India, emphasizing the importance of a smooth transition towards online learning. A survey to gauge the current perception towards online learning, drawbacks of it, and also the preferred mode of learning was done, which gives a great insight into what factors affect the success of online learning. Similar survey-based research has been done by Basilaia and Kvavadze (2020) with great emphasis on the transition to online learning in Georgia. A brief discussion on the social impact of this immediate transition from classroom learning to online learning has been done by Kufi et al. (2020) along with the importance of free online courses and how resource use should be done in schools to tackle this situation.

\subsection{E-learning}

Harper et al. (2004) explain distance learning, the advancement of the same along with the impact of government involvement on distance learning. The authors embellish the current details with information on the role of participants in the success of distance learning, change in the organizational structure required for the success of distance learning, and the pros and cons of it in long term perspectives. Along similar lines, Au et al. (2018) discuss the success factors for students learning online such as time management, online examination conduction and flexibility. Jones et al. (2014) discuss how the introduction of technology affects the temporal experience of the learner and states the importance of time flexibility which must be introduced in online learning. This, in a direct sense, gives an understanding of how synchronous and asynchronous ways of teaching can affect the learning capacity of a student. Though Fang et al. (2019) discuss the evolution of MOOCs from 2009 to 2018 in language learning through literature study, they also reiterate similar points and their results show that online learning courses and platforms have raised the time and space for learning, which has made it flexible.

Veletsianos and Houlden (2019) have discussed various themes associated with distance learning. These themes have been closely associated with flexibility and further discuss various approaches towards it from a pedagogical, liberal, temporal and cultural point of view for the past 40 years of distance learning. A similar analysis of the flexibility of transactional education has been done by Paulet al. (2015). Even Naidu (2019) has given a brief overview of how open learning, flexible learning, and e-learning are very dynamic
Systematic research of e-learning platforms

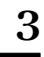


AAOUJ 16,1

with narrative changing at any given point of time. Its psychological impact on students also has been reviewed along with various advantages and disadvantages of it. A similar yet a very unique study also has been done by Estacio and Raga (2017), where they have used machine learning models and correlated the quantitative data available from Moodle to the online learning behavior of students, where the grades obtained are used as a determining medium.

Major et al. (2014) explained the various pedagogical approaches which can be used in distance learning like constructivist, problem-based learning, holistic approach, teamwork. They further provided an overview of how the transition to the online setting must be done along with the technological challenges associated with it. Joanna Rabiega-Wiśniewska (2020) conducted a case study on the current perception of e-learning at Maria Grzegorzewska University, Poland. The study does indicate a neutral stance over liking of the immediate change in learning method, but with $91 \%$ of students having a stable Internet connection; it's a good sign nonetheless. A brief understanding of the type of scaling system to be used in such surveys has been explained, which shall be imbibed in this paper to enhance and avoid response bias and to evaluate NPS. Marengo and Marengo (2005) have discussed in brief the actual organizational structure and proper education requirements through Kirkpatrick's taxonomy which needs to be imbibed in e-learning. The concept of blended learning also has been introduced in this paper with its pros and cons in economic terms. The study has effectively discussed various costs involved in e-learning along with the benefits gained. These costs have played an important role in deciding parametric questions to be asked to the students for correct evaluation of the current perception of e-learning tools among engineering students.

2.3.1 Comparison of online platforms for e-learning. A comprehensive comparative study becomes crucial to determine the publicly known best available tools as floating a survey on the unpopular tools may hamper the survey outcome significantly. To aid this comparison, identification of parameters to be compared must be identified. Agrawal et al. (2016) discuss in brief how a parametric survey needs to be conducted and the importance of information quality, service quality, system quality in the success of elearning. Further, James-Gordon et al. (2003) explain the importance of security features required for e-learning to not be a hindrance for people and an understanding of how market demand or the popularity of a learning platform affects its overall success. Wong (2015) mentions the importance of flexibility of the platforms provided for MOOCs and this flexibility will play a big role in these e-learning platforms as well. Keeping these factors in mind, various parameters such as features provided, platforms which the tool supports, typical customers the tool attracts, customer support provision, price of the tool, overall customer perception about the tool, third party integration, the scope of the tool have been devised for comparison.

2.3.2 Comparison of survey methods. Surveys can be conducted in two ways: online and offline. Offline surveys are generally avoided as they have a localized outreach and getting timely responses is a big task. Online surveys break the barriers of distance and have a hassle-free response collection process. Online survey forms have an easy build coupled with cost-effectiveness. There are various online survey platforms available and a proper comparison must be done among them to find out an apt option for the survey.

To accurately garner student perceptions, the online survey tool should be selected with keen consideration. Along with cost-effectiveness, this tool should bring the magical combination of accuracy and customization. To narrow down on the best survey tool, it was necessary to adopt a comprehensive approach that compared these tools based on the parameters like permissible number of questions, permissible number of responses, data export availability and options, number of free surveys allowed, customization and its scale. Table 1 displays the permissible values with the free version of the tool along with the cost to upgrade to the premium version. 


\begin{tabular}{|c|c|c|c|c|c|c|c|c|}
\hline $\begin{array}{l}\text { Sr. } \\
\text { No } \\
\end{array}$ & Name & Questions & Respondents & $\begin{array}{l}\text { Data } \\
\text { export }\end{array}$ & $\begin{array}{l}\text { Number of } \\
\text { surveys }\end{array}$ & Customization & $\begin{array}{c}\text { Premium } \\
\text { version } \\
(\$ / \text { month })\end{array}$ & $\begin{array}{l}\text { Systematic } \\
\text { research of } \\
\text { e-learning }\end{array}$ \\
\hline 1 & $\begin{array}{l}\text { Google } \\
\text { Forms }\end{array}$ & Unlimited & Unlimited & Yes & Unlimited & Yes & 0 & platforms \\
\hline 2 & QPoint & 10 & 500 & Yes & Unlimited & Yes & 200 & \\
\hline 3 & Feedier & Unlimited & Unlimited & Yes & 1 & Yes & 30 & 5 \\
\hline 4 & $\begin{array}{l}\text { Survey } \\
\text { Monkey }\end{array}$ & 10 & 100 & No & Unlimited & No & 26 & \\
\hline 5 & Typeform & Unlimited & 100 & Yes & Unlimited & Yes & 29 & \\
\hline 6 & $\begin{array}{l}\text { Survey } \\
\text { Legend }\end{array}$ & Unlimited & Unlimited & No & 3 & Yes & 15 & \\
\hline 7 & Polldaddy & Unlimited & Unlimited & No & Unlimited & No & 17 & \\
\hline 8 & $\begin{array}{l}\text { Survey } \\
\text { Planet }\end{array}$ & Unlimited & Unlimited & No & Unlimited & No & 15 & \\
\hline 9 & Survey Nuts & 10 & Unlimited & No & Unlimited & No & 17 & Comparison of survey \\
\hline 10 & CrowdSignal & Unlimited & Unlimited & No & Unlimited & No & 17 & platforms based on \\
\hline 11 & SoGoSurvey & Unlimited & 100 & Yes & 2 & Yes & 25 & features \\
\hline
\end{tabular}

\section{Methodology}

3.1 Data collection tool

A comprehensive study of seven e-learning platforms (Zoom, Google Meet, Microsoft Teams, GoToWebinar, Zoho Meeting, Adobe Connect and GoToMeeting) was performed to gauge the consistency and performance of platforms based on features, security, customer support and third-party integrations. This study acted as predictive analysis to understand what could be the student's standpoint and then understand how much it varies. Further, a comparative analysis was adopted to find the most suitable online survey platform. A survey-based approach was adopted to gauge the perception of engineering students on the available e-learning tools. Through the review done above, Google Forms was finalized as the survey platform.

\subsection{Questionnaire for survey}

For drawing valuable insights, it is vital to analyze the most critical parameters. A respondent friendly survey was constructed on Google Forms wherein the respondents had to rate the e-learning platforms based on the parameters like video quality, audio quality, privacy/security, multi-device support, user-friendliness of the interface, screen sharing, chat features, host's control and quality of meeting recording. Figure 1 shows the flow of the questionnaire.

The questionnaire ratings were taken on a five-point Likert scale developed by Rensis Likert (Reichheld, 2003) as this type of scale is used in attitude research projects (Joanna Rabiega-Wiśniewska, 2020). An odd-numbered Likert scale was used to avoid emotion bias and to provide an option for indecision, negativity, and positivity (Croasmunand Ostrom, 2011).

\subsection{Distribution channel}

A robust distribution channel ensures a greater number of responses from students, spread across various engineering colleges and branches. To achieve the same, the survey form was circulated through platforms like WhatsApp, Gmail, Instagram, LinkedIn and personal calling.

These tools and methods helped in collecting responses from students spread across 12 branches and 49 colleges. The responses generated from surveys generally depict a bell curve. In such cases, if the sample size or the number of respondents is very large, the confidence interval narrows down and errors decrease. Error reduction is good, but the 


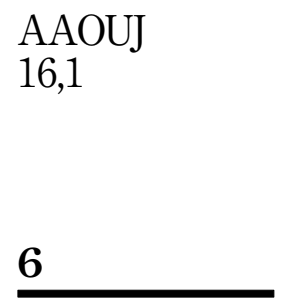

Figure 1.

Questionnaire flow chart

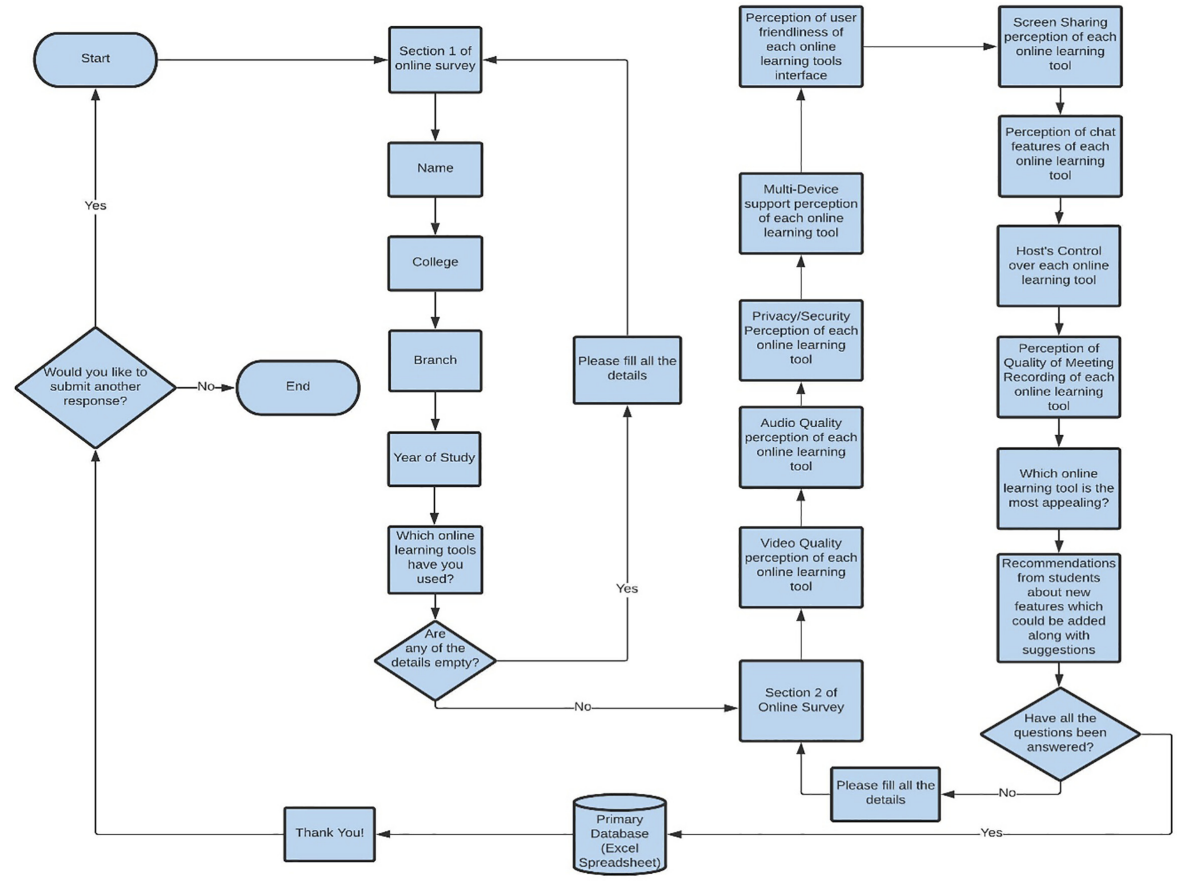

confidence interval should not decrease to a point where it starts showing that negligible people have positive responses. Now, with a decrease in sample size, the confidence interval increases but the error also increases. Thus, selecting the number of respondents is a doubleedged sword as a perfect balance has to be struck among confidence interval and error. Hence, an optimal range of 350-400 responses was chosen and the survey form was closed on receiving 364 responses.

\section{Data analysis}

\subsection{Respondents profiles}

A total of 364 responses were collected from 49 colleges across India. It was ensured that all the respondents have extensively used the platforms voted by them for at least a month. This data needs to be sorted into various categories to identify trends and gain insights from them. These responses were analyzed branch-wise and year-wise to check whether there is slight response bias, to identify trends, and to draw insights based on the same (see Figures 2 and 3).

The Mechanical branch accounted for $44.23 \%$ of responses and had the maximum number of responses. Computer Science and Engineering (CSE) branch was second to the Mechanical branch and held $23.07 \%$ of responses. Information Technology (IT) branch and Electronics and Telecommunication branch (EXTC) had an almost similar number of respondents and contributed 9.89 and $9.07 \%$ of responses respectively. This does indicate that the perception generated was slightly biased towards the requirements of Mechanical Engineering students, but on a closer look at the data, the platforms selected and the ratings given by other branches were on similar lines as the Mechanical branch. Last year students of engineering submitted the maximum responses indicating that maximum awareness, for 

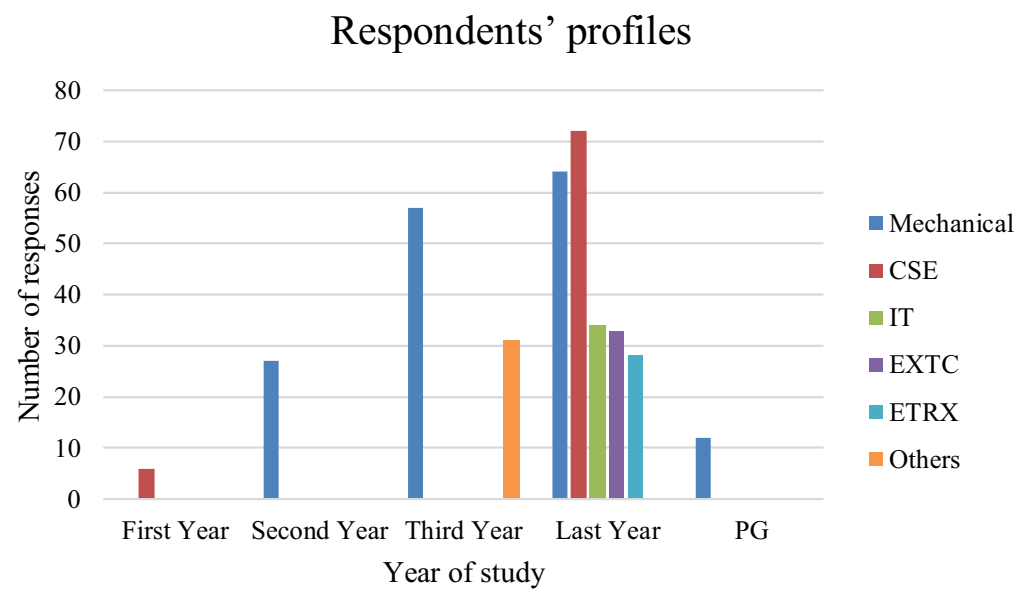

Systematic research of e-learning platforms

- Mechanical

- CSE

Overall aspect comparison

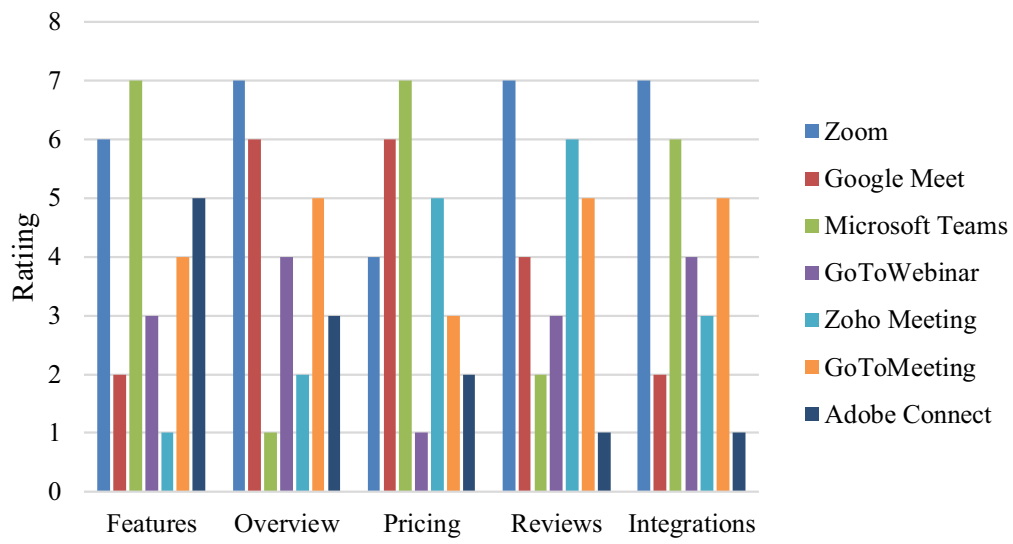

Figure 2. Respondents' profiles

Figure 3. Overall aspect comparison of platforms (Individual platform level comparison is given in Appendix)

now, has been limited to certain students only with the further scope for improvement. As first-year students had just been admitted to their respective colleges when the survey was conducted, they were not exposed to the e-learning environment thus resulting in a fewer number of responses from the first year.

\subsection{Net promoter score of platforms}

The data, collected from the survey responses of 364 students, was analyzed firstly by segregating and making a college wise distribution of responses to check the demographic reach of the survey. A wider demographic reach ensures a varied perspective thereby eliminating regional bias. Branch wise distribution of responses was also plotted to check for singular branch bias for a particular online learning tool. A similar approach was used to check singular year bias by plotting the year-wise distribution of responses. This data was crucial in understanding how the perception is influenced by branch and year of study. 
AAOUJ

16,1

8

Awareness of platforms was analyzed to check the popularity or reach of each platform irrespective of its liking or disliking. The average ratings of each platform based on the nine parameterized survey outcomes provided insights as to which platform has been consistent in providing all the features satisfactorily to its target audience.

Further, an NPS for each online learning platform was evaluated. NPS is a loyalty index introduced by Frederick F. Reichheld in 2003, primarily used to evaluate how much a product has been liked by the customers and can be used for further product referrals. Promoters are individuals who strongly recommend the product and are convinced of the parameter, thus rating it 4 or 5 . Detractors are individuals who are unsatisfied with the product or some parameter of it, thus rating it 1 or 2 . Individuals, who give a rating of 3 , lie between these two categories and are called passives. NPS for a particular platform, on a 5-point Likert scale, is evaluated as:

$$
\mathrm{NPS}=\frac{(\text { Number of promoters }- \text { Number of detractors }) * 100}{\text { Number of respondents who have used that platform }}
$$

NPS calculated was classified as per the following ranges:

(1) (-100 to 0$)$ : Needs improvement

(2) (0-30): Good

(3) (30-70): Very good

(4) (70-100): Excellent

The above ranges helped to boil down the overall user sentiment into a single quantifiable value and classify the platform on the same. Finally, the preference percentage was plotted for each platform to understand the current perception and to recognize which platform currently is ruling the roost in the online learning world among engineering students.

\section{Results and interpretations}

\subsection{Internal study outcomes}

The internal study focused on performing a comparative analysis of the available e-learning platforms. By comparing these platforms based on the offered features, integrations, reviews, and pricing, the study aimed at finding a platform that provided a complete package to its users at a reasonable subscription cost. Table 2 provides an overview of the internal study outcome.

From Table 2, it is evident that Zoom and Microsoft Teams are the best platforms with 44 and 67 features available respectively. A closer introspection does reveal a shortcoming of Microsoft Teams over Zoom that is the absence of an attendance management system. In terms of security aspects, Google Meet, GoToMeeting, and GoToWebinar do not have access

Table 2.

Overall comparison of platforms

\begin{tabular}{llccccccc}
\hline $\begin{array}{l}\text { Sr. } \\
\text { No }\end{array}$ & Parameters & Zoom & $\begin{array}{c}\text { Google } \\
\text { Meet }\end{array}$ & $\begin{array}{c}\text { Microsoft } \\
\text { Teams }\end{array}$ & GoToWebinar & $\begin{array}{c}\text { Zoho } \\
\text { Meeting }\end{array}$ & $\begin{array}{c}\text { Adobe } \\
\text { connect }\end{array}$ & GoToMeeting \\
\hline 1 & Features & 6 & 2 & 7 & 3 & 1 & 5 & 4 \\
2 & Overview & 7 & 6 & 1 & 4 & 2 & 3 & 5 \\
3 & Pricing & 4 & 6 & 7 & 1 & 5 & 2 & 3 \\
4 & Reviews & 7 & 4 & 2 & 3 & 6 & 1 & 5 \\
5 & Integrations & 7 & 2 & 6 & 4 & 3 & 1 & 5 \\
6 & Total & 31 & 20 & 23 & 15 & 17 & 12 & 22 \\
\hline
\end{tabular}


control and an activity dashboard thereby making these platforms weak. The only salvation for Google Meet is that it has a better API. A bird's eye view indicates that Google Meets supports all the platforms available to people, whereas Zoom and Microsoft Teams do not support the Windows phone app. Microsoft Teams does not attract freelancers and does not provide customer support over the phone. Other platforms satisfactorily provide this, thereby leaving Microsoft Teams with a massive scope of improvement in this aspect. Google Meet is the best in this aspect followed closely by Zoom.

As visible from both Table 3, Microsoft Teams is the most feasible platform whereas GoToWebinar is the highest priced platform. Zoom and Google Meet are also priced affordably but Microsoft Teams wins the battle in pricing. Table 4 shows that the rankings of all the platforms are not too bad, all crossing 4 stars, but the number of reviews given for Zoom and Google Meet shows that they are the most popular platforms among the others. Zoho Meeting though not as popular, has been highly ranked by those who have used it. Zoom and Google Meet are closely followed by Microsoft Teams which ranks third in popularity. The pricing of GoToWebinar and Adobe Connect does surely reflect their lack of popularity amongst general people. Table 4 does show that Zoom is the platform with the highest number of Third-Party Integrations amounting to whopping 170 integrations. It is closely followed by Microsoft Teams with 154 Third-Party integrations. Other platforms need improvements in this aspect

\begin{tabular}{|c|c|c|c|c|c|c|c|}
\hline Features & Zoom & $\begin{array}{l}\text { Google } \\
\text { Meet }\end{array}$ & $\begin{array}{l}\text { Microsoft } \\
\text { Teams }\end{array}$ & GoToWebinar & $\begin{array}{c}\text { Zoho } \\
\text { Meeting }\end{array}$ & $\begin{array}{l}\text { Adobe } \\
\text { Connect }\end{array}$ & GoToMeeting \\
\hline API* & $\boldsymbol{\nu}$ & $\nu$ & $\nu$ & $x$ & $\boldsymbol{\nu}$ & $\boldsymbol{\nu}$ & $\boldsymbol{\nu}$ \\
\hline Access control & $\boldsymbol{}$ & $x$ & $\boldsymbol{\nu}$ & $x$ & $\boldsymbol{\nu}$ & $x$ & $x$ \\
\hline $\begin{array}{l}\text { Activity } \\
\text { dashboard }\end{array}$ & 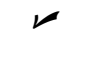 & $x$ & $\nu$ & $x$ & $x$ & $\nu$ & $x$ \\
\hline $\begin{array}{l}\text { Attendance } \\
\text { management }\end{array}$ & $v$ & $x$ & $x$ & $\boldsymbol{\nu}$ & $v$ & $x$ & $x$ \\
\hline $\begin{array}{l}\text { Automatic } \\
\text { notifications }\end{array}$ & $\nu$ & $x$ & 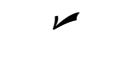 & $x$ & $x$ & $x$ & $x$ \\
\hline $\begin{array}{l}\text { CRM } \\
\text { integration }\end{array}$ & V & $x$ & $\nu$ & $x$ & $v$ & $x$ & $x$ \\
\hline Chat & $\boldsymbol{\nu}$ & レ & $\nu$ & $x$ & $x$ & $\boldsymbol{\nu}$ & レ \\
\hline $\begin{array}{l}\text { Collaboration } \\
\text { tools }\end{array}$ & $\nu$ & $\nu$ & $\nu$ & $x$ & $\nu$ & $v$ & $v$ \\
\hline $\begin{array}{l}\text { Collaborative } \\
\text { workspace }\end{array}$ & $v$ & $x$ & $\nu$ & $x$ & $x$ & $\nu$ & $x$ \\
\hline Commenting & レ & $x$ & レ & $x$ & レ & $x$ & $x$ \\
\hline $\begin{array}{l}\text { Two-way audio } \\
\text { and video }\end{array}$ & $v$ & $\ddot{\nu}$ & $\nu$ & $\ddot{v}$ & $v$ & $\ddot{v}$ & $\ddot{v}$ \\
\hline $\begin{array}{l}\text { User } \\
\text { management }\end{array}$ & $\nu$ & $x$ & 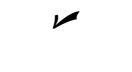 & $x$ & $x$ & 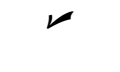 & $x$ \\
\hline $\begin{array}{l}\text { Video call } \\
\text { recording }\end{array}$ & $\nu$ & $\checkmark$ & $x$ & 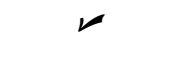 & $x$ & $v$ & $\nu$ \\
\hline $\begin{array}{l}\text { Video } \\
\text { conferencing }\end{array}$ & $\nu$ & $レ$ & V & 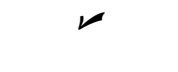 & $\nu$ & $x$ & $\nu$ \\
\hline $\begin{array}{l}\text { Video } \\
\text { streaming }\end{array}$ & $\nu$ & $\nu$ & $x$ & $v$ & $x$ & $x$ & $v$ \\
\hline $\begin{array}{l}\text { Total features } \\
\text { (source: getapp. } \\
\text { com) }\end{array}$ & 44 & 12 & 67 & 23 & 13 & 29 & 21 \\
\hline
\end{tabular}

Note(s): *API- Application programming interface is a software intermediary that defines interactions between software
Systematic research of e-learning platforms
Table 3.

Feature-based comparison of platforms 


\begin{tabular}{l} 
AAOUJ \\
16,1 \\
$\mathbf{1 0}$ \\
\hline
\end{tabular}

Table 4.

Parameterized comparison of platforms

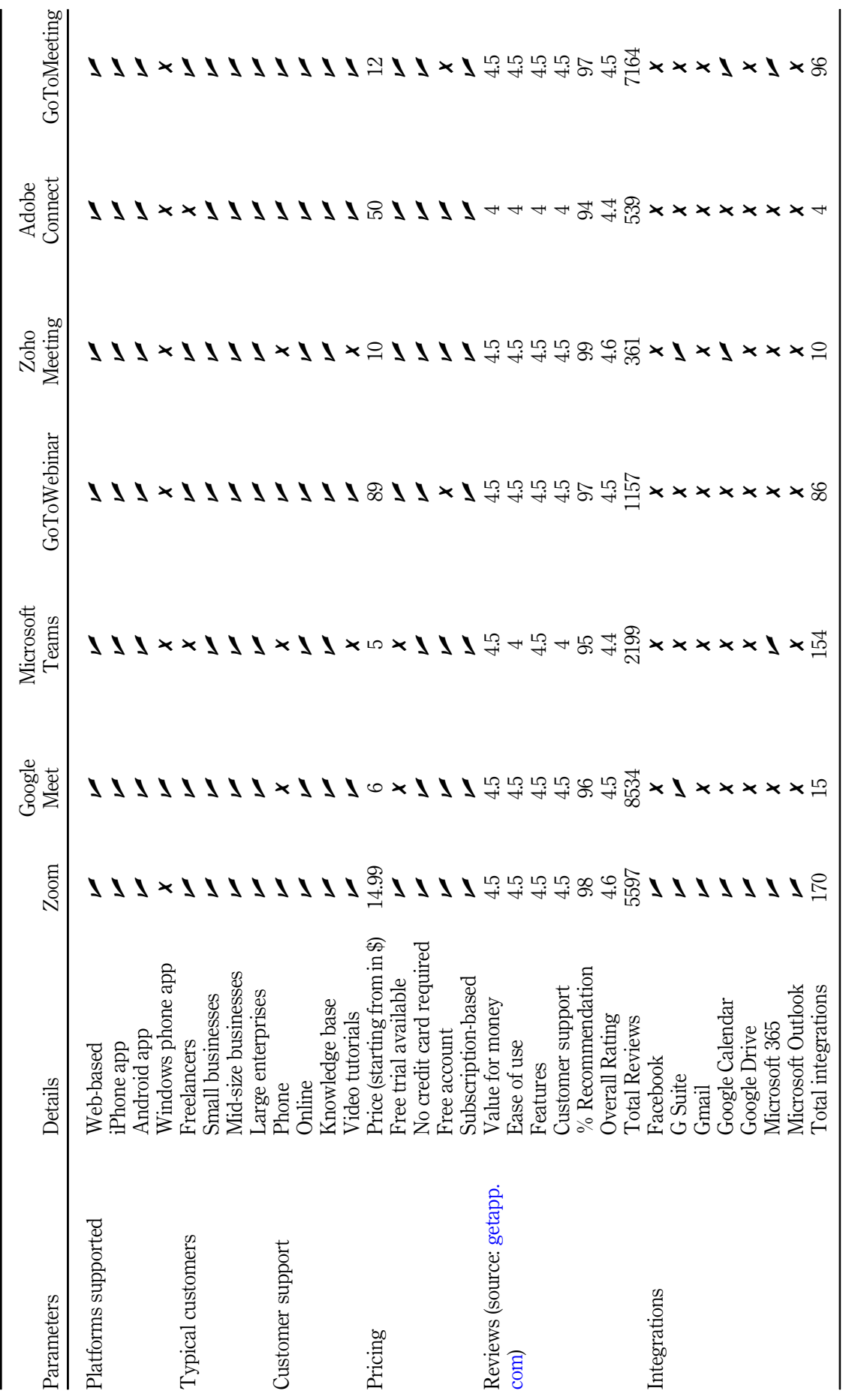


with 86 integrations from GoToWebinar and then an equally shocking drop to 15 integrations from Google Meet. This does show that Third-Party Integrations are surely a challenge for these platforms, Zoom and Microsoft Teams being the only exceptions.

These results show that Zoom has the best balance among features, overview, pricing, popularity, third-party integrations as compared to other platforms. Though just by score value, Microsoft Teams should have followed as the next best; the graph shows high inconsistencies in these parameters. This indicates that due notice over certain parameters has not been given in Microsoft Teams. This makes Google Meet slightly more favorable over Microsoft Teams. Adobe Connect and Zoho Meeting do not make a case to prove their chance in the education sector with even GoToWebinar becoming a rare case of use due to its high price (see Figures 4-6).

\subsection{Awareness of platforms}

Zoom and Google Meets are the most publicly known platforms with an astounding awareness percentage of 86 and $81.6 \%$ respectively. Adobe connect and Zoho Meeting is the least known ones and the perception matches the internal study where the higher pricing and fewer features value seen in the graph of these tools had made them possibly least known ones. Thus, there are increased chances of Google Meets and Zoom ruling the roost in the online education industry as these are the platforms mostly used (see Table 5).

\subsection{Comparison of platforms based on survey results}

These ratings indicate that Microsoft Teams is the best platform followed by Google Meets, Zoom, GoToWebinar, GoToMeeting, Zoho Meeting and Adobe Connect. Microsoft Teams had a maximum rating of 3.46 closely followed by Google Meets with a rating of 3.45. No platform had an average rating beyond 4 . These passive ratings indicate an even greater perspective over the audience being a low tolerant one with a keen eye towards perfection. Considering this it can be predicted that the NPS would not be very high and in a rare case, it would breach the barrier of 30 (see Table 6).

\subsection{Net promoter score}

Microsoft Teams has the maximum NPS of 30.36, overcoming the Good band and entering the Very Good band. Adobe Connect has the worst NPS of -50 indicating that it needs

\section{Platform awareness among respondents}

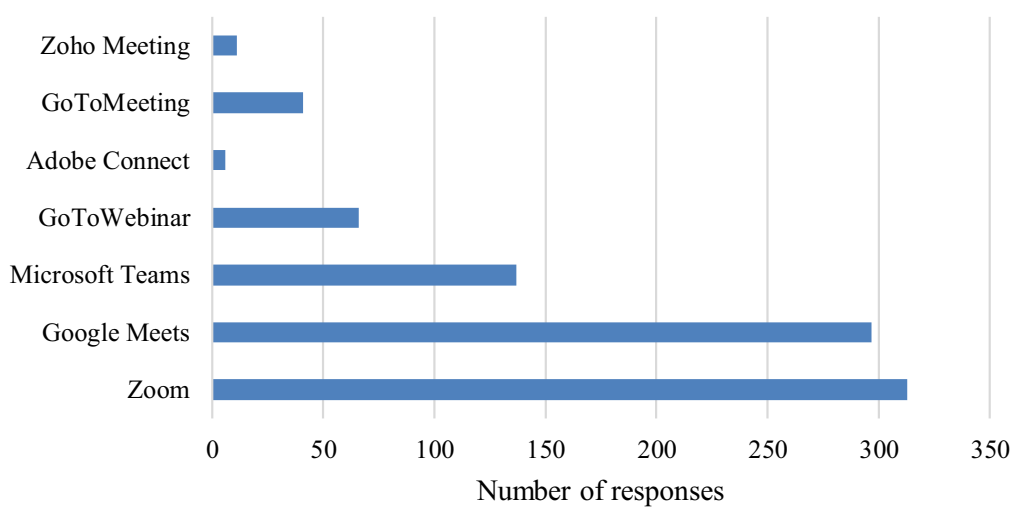

Figure 4. Platform awareness among respondents
Systematic research of e-learning platforms 


\section{AAOUJ}

16,1

\section{2}

Figure 5.

Average survey ratings (For individual platform level comparison, see Appendix)

Figure 6.

Platform-based average survey ratings

\section{Average survey rating}

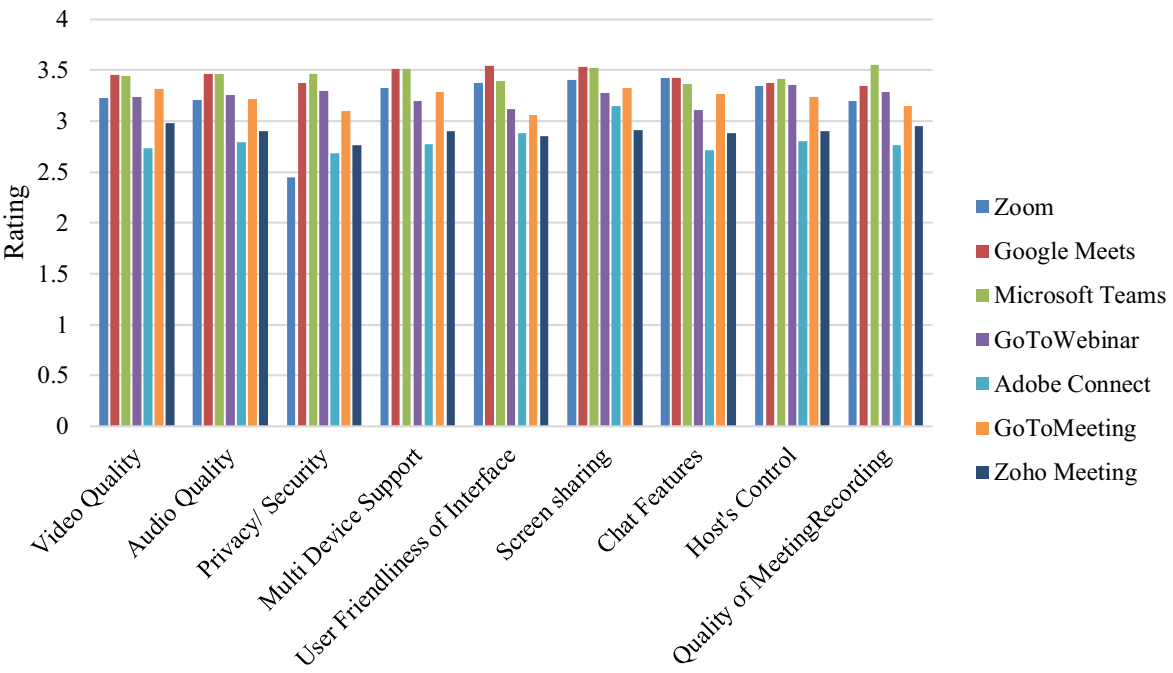

\section{Platform based average survey ratings}

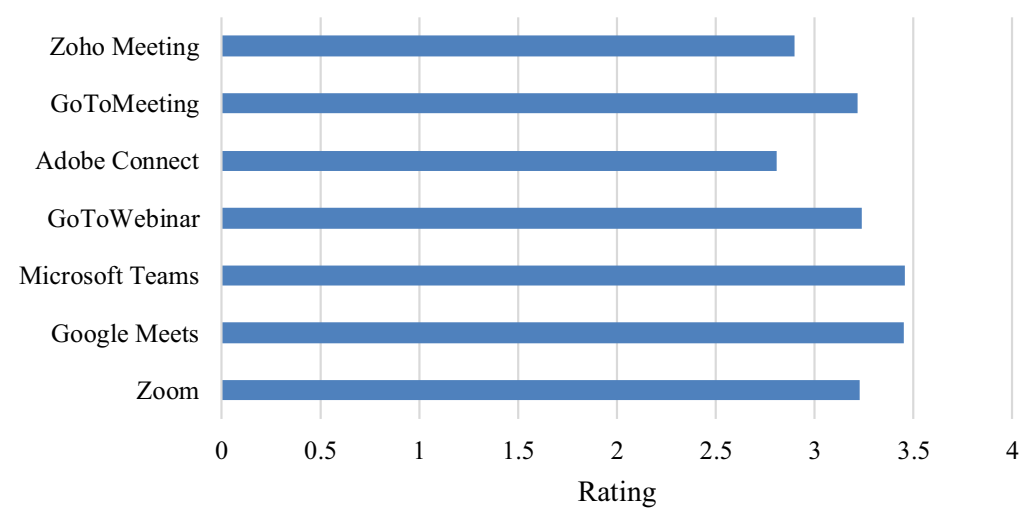

improvement. Also, the NPS of almost all platforms is closely ranged showing that the competition is very stiff (see Figures 7 and 8).

\subsection{Preference of platforms}

A majority of the audience has given preference to Google Meets followed by Zoom and Microsoft Teams respectively. Here, though the quality of Microsoft Teams is much higher than that of both Zoom and Google Meets, lack of awareness of Microsoft Teams has resulted in it being ruled out of favor. There is also a curious case of Zoom, but a closer introspection shows that concerns over privacy and security of the platform have caused it to be not as favorable as Google Meet, though being superior in other features. Zoho Meetings and Adobe Connect have not made it through as far as students' preference is concerned. 


\section{AAOUJ 16,1}

\section{Challenges and solutions}

The survey respondents highlighted several shortcomings which were barring them from having an effective e-learning experience. Along with these shortcomings, the respondents expressed their desire for certain additional features which would greatly boost the e-learning experience.

\section{4}

\subsection{Security concerns}

A high number of students are attending digital classrooms and it has become easier for cybercriminals to hijack meetings. Events of video hijacking by uninvited parties to disrupt the usual proceedings have been on the rise since the global quarantine began. Spreading hateful comments, racist and obscene content on these platforms has given rise to a new kind of Internet trolling. Further, unwarranted logins to the enterprise cloud architecture have resulted in immense data breaches.

To greatly reduce such malpractices, the responsibility lies on the shoulders of the platform, the host, and the attendees. Platforms have been striving to enhance their security measures and have also created robust privacy policies. Hosts should secure meetings with a passcode and use private distribution channels to invite participants. Also, disabling features like join before host and participant screen sharing would provide a greater immunity against

\begin{tabular}{lrcccccc}
\hline Features & One & Two & $\begin{array}{c}\text { Ratings } \\
\text { Three }\end{array}$ & Four & Five & Do not know & NPS \\
\hline Video Quality & 5 & 31 & 42 & 58 & 28 & 201 & 36.24 \\
Audio Quality & 8 & 27 & 45 & 45 & 36 & 204 & 33.34 \\
Privacy/Security & 7 & 28 & 44 & 35 & 39 & 212 & 28.27 \\
Multi-Device Support & 10 & 19 & 44 & 40 & 38 & 214 & 35.51 \\
User Friendliness of Interface & 13 & 28 & 44 & 41 & 40 & 199 & 28.99 \\
Screen Sharing & 8 & 25 & 39 & 38 & 41 & 214 & 33.34 \\
Chat Features & 13 & 29 & 45 & 34 & 40 & 204 & 23.19 \\
Host's Control & 12 & 24 & 41 & 29 & 40 & 219 & 23.92 \\
Quality of Meeting Recording & 6 & 25 & 32 & 34 & 39 & 229 & 30.44 \\
Average & 10 & 27 & 42 & 40 & 38 & 211 & 30.36 \\
\hline
\end{tabular}

Table 6.

Feature-based NPS calculation for Microsoft teams (NPS calculations of other platforms given in Appendix)

\section{NPS based comparison of platforms}

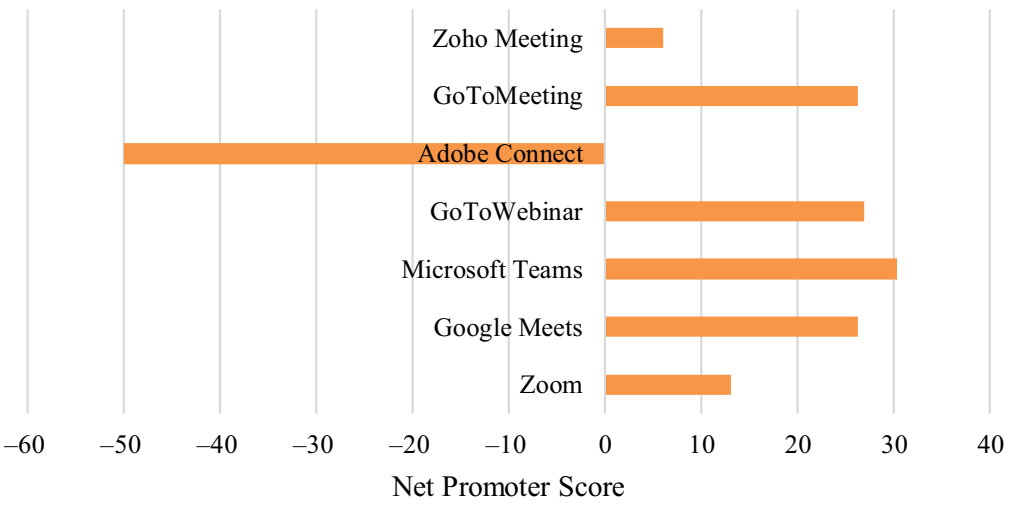

Figure 7.

Comparison of platforms based on NPS 


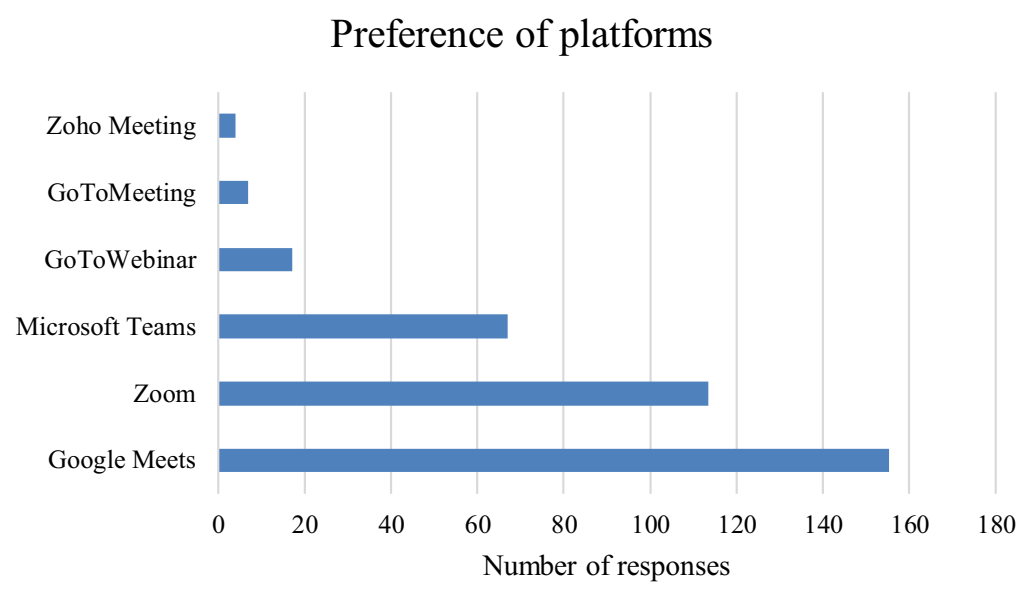

Systematic

research of

e-learning

platforms

15

hijacking. Attendees should refrain from sharing the meeting details on public platforms and avoid clicking on any malicious links.

\subsection{Online engagement concerns}

6.2.1 Proctor mode. After spending huge amounts on these e-learning platforms, educational institutions do not prefer using separate applications designed specifically for proctoring. This leaves them with two broad options which are to either conduct examinations without proctoring or to use the same e-learning platform for proctoring. The former invites a large number of unfair practices and thus is unjust for diligent students (Nguyen, 2015). The latter requires all the participants to switch on their video which consumes a great amount of bandwidth resulting in lags. Even if incoming videos are disabled, the bandwidth problem persists with the host which leads to difficulties in proctoring (Gillett-Swan, 2017; Dhawan, 2020). Thus, the introduction of a specialized proctor mode on these platforms is a desire of many students.

6.2.2 Lecture mode. Survey respondents reported that mischiefs by certain students (e.g.: disturbing annotations on the screen, muting the instructor, etc.) disrupt the flow of the lectures. Though the platforms have provided certain host-specific features, the spontaneous virtualization of education resulted in the instructors getting insufficient time to adapt themselves to these features. This issue has also been highlighted by Moradimokhles and Hwang (2020) as a limitation of online learning. As a result, a majority of them are not aware of or are unable to use all the features they have at their disposal. Even before the pandemic hit, this adaptability was an issue that was highlighted by Parkes et al., (2014). As a result, a majority of them are not aware of or are unable to use all the features they have at their disposal. Bringing all these features under a single button of lecture mode would thus help in conducting lectures smoothly without mischiefs.

\subsection{Introduction of new features}

In addition to the existing features, the respondents expressed the need for certain features. A large number of instructors annotate the content to provide a lucid explanation. However, the students can download the file without any annotations. An option to download it with annotations would ensure a quicker grasping of the concept when students revisit that concept. An inbuilt notepad that can be opened along with the lecture content, in a split-screen mode, would make the notes taking process hassle-free. Live polling would facilitate the instructor in a variety of ways. Similarly, live quizzes with leader-boards would not only add 
AAOUJ

16,1

an element of fun to the learning but would also be an indicator of how much the students have learned (Huang et al. (2019a, b), Seaborn and Fels (2015)). The platforms should further be compatible with augmented reality and virtual reality as these would greatly increase the level of understanding (Bower, 2017; El Kabtane et al., 2019; Uhomoibhi et al., 2019). The presence of a virtual user guide along with a chat box would help in resolving the basic issues faced by a great number of users. The ability to rewind live lectures, like YouTube Live, would help students who have missed out on certain important parts of a lecture.

\section{Conclusion}

Almost all the platforms are sufficient for learning for the time being but have shortcomings that need to be improved to adapt to this fast-changing education sector. There is a large amount of concern over the video and audio quality of all the platforms and the students feel that the platforms are not updated as per current requirements. As per this research study, Google Meet is the best platform among students followed by Zoom and Microsoft Teams respectively, even though NPS indicates Microsoft Teams is the best. If Microsoft teams can improve its social presence, it can prove to be a strong competitor for both Zoom and Google Meet.

The available online learning tools are not the best means to study a holistic curriculum of theory and practical combined. These tools will have to be more adaptable, more technically friendly for the audience to achieve high effectiveness. Along with online learning, methods to improve motivation to study through these means need to be developed (Roberts et al., 2018). Available e-learning tools serve the basic purpose but integrations of these platforms with other platforms must be improved to give a wider, more enriching experience. Keeping these points in mind, it would not be wrong to conclude that currently, online learning is the best bet left to counter this unprecedented situation in India, but infrastructure development for such platforms needs to be enhanced to consider this method of learning completely fruitful.

\section{Limitations and future scope}

This research is based on the perceptions of engineering students hailing majorly from Indian cities and is thus subject to educational stream bias and geographical bias. Curbing the educational stream bias by incorporating respondents from other streams could help in understanding the shortcomings on a broader level. Expanding the respondent base by breaking the geographical barriers would help in further understanding the overall access to technology and its implications on the e-learning experience. Furthermore, the overall experience, perceptions, and awareness of students about these platforms are subject to the instructor's ICT proficiency along with the availability and compatibility with the existing infrastructure in the institutions. Considering the unequal penetration of technology across the various socioeconomic classes, an equal amount of focus should be laid on bridging these gaps (Zhao, 2016). As the COVID-19 pandemic is heralding the end of a largely obsolete educational system, developing solutions on a global level while keeping in mind the issues on local levels would bolster the possibility of redesigning a better education system on the bedrocks of equity, excellence and student well-being.

\section{References}

Agrawal, V., Agrawal, A. and Agarwal, S. (2016), "Assessment of factors for e-learning: an empirical investigation”, Industrial and Commercial Training, Vol. 48 No. 8, pp. 409-415. 
$\mathrm{Au}$, O.T.S., Li, K. and Wong, T.M. (2018), "Student persistence in open and distance learning: success factors and challenges", Asian Association of Open Universities Journal, Vol. 13 No. 2, pp. 191-202.

Azorín, C. (2020), "Beyond COVID-19 supernova. Is another education coming?", Journal of Professional Capital and Community. doi: 10.1108/JPCC-05-2020-0019.

Systematic

research of

e-learning

platforms

Barak, M. (2013), "Teaching engineering and technology: cognitive, knowledge and problem-solving taxonomies", Journal of Engineering, Design and Technology, Vol. 11 No. 3, pp. 316-333.

Basilaia, G. and Kvavadze, D. (2020), "Transition to online education in schools during a SARS-CoV-2 coronavirus (COVID-19) pandemic in Georgia”, Pedagogical Research, Vol. 5 No. 4, pp. 1-9.

Bower, M. (2017), "Designing for learning using virtual worlds", Design of Technology-Enhanced Learning, Emerald Publishing Limited, pp. 305-364.

Carter, R.A. Jr, Rice, M., Yang, S. and Jackson, H.A. (2020), "Self-regulated learning in online learning environments: strategies for remote learning”, Information and Learning Sciences, Vol. 121 No. 5, pp. 321-329.

Choudhury, P.K. (2019), "Student assessment of the quality of engineering education in India: evidence from a field survey", Quality Assurance in Education, Vol. 27 No. 1, pp. 103-126.

Croasmun, J.T. and Ostrom, L. (2011), "Using likert-type scales in the social sciences", Journal of Adult Education, Vol. 40 No. 1, pp. 19-22.

Dhawan, S. (2020), "Online learning: a panacea in the time of COVID-19 crisis", Journal of Education Technology Systems, Vol. 49 No. 1, pp. 5-22.

El Kabtane, H., El Adnani, M., Sadgal, M. and Mourdi, Y. (2019), "Augmented reality-based approach for interactivity in MOOCs", International Journal of Web Information Systems, Vol. 15 No. 2, pp. 134-154.

Estacio, R.R. and Raga, R.C. Jr (2017), "Analyzing students online learning behavior in blended courses using Moodle”, Asian Association of Open Universities Journal, Vol. 12 No. 1, pp. 52-68.

Fang, J.W., Hwang, G.J. and Chang, C.Y. (2019), "Advancement and the foci of investigation of MOOCs and open online courses for language learning: a review of journal publications from 2009 to 2018”, Interactive Learning Environments, pp. 1-19, doi: 10.1080/10494820.2019.1703011.

Fuentes-Del-Burgo, J. and Navarro-Astor, E. (2016), "What is engineering education for? Listening to the voices of some Spanish building engineers", Journal of Engineering, Design and Technology, Vol. 14 No. 4, pp. 897-919.

Fullan, M. (2020), "The battle of the century: catastrophe versus evolutionary nirvana", Australian Education Leader, Vol. 42 No. 1, pp. 8-10.

Gambhir, V., Wadhwa, N.C. and Grover, S. (2016), "Quality concerns in technical education in India", Quality Assurance in Education, Vol. 24 No. 1, pp. 2-25.

Gillett-Swan, J. (2017), "The challenges of online learning: supporting and engaging the isolated learner", Journal of Learning Design, Vol. 10 No. 1, pp. 20-30.

Harper, K.C., Chen, K. and Yen, D.C. (2004), "Distance learning, virtual classrooms, and teaching pedagogy in the Internet environment", Technology in Society, Vol. 26 No. 4, pp. 585-598.

Hillier, M. (2018), "Bridging the digital divide with off-line e-learning", Distance Education, Vol. 39 No. 1 , pp. $110-12$.

Hollweck, T. and Doucet, A. (2020), "Pracademics in the pandemic: pedagogies and professionalism", Journal of Professional Capital and Community, pp. 1-11.

Huang, B., Hew, K.F. and Lo, C.K. (2019a), "Investigating the effects of gamification-enhanced flipped learning on undergraduate students' behavioral and cognitive engagement", Interactive Learning Environments, Vol. 27 No. 8, pp. 1106-1126.

Huang, B., Hwang, G.J., Hew, K.F. and Warning, P. (2019b), "Effects of gamification on students' online interactive patterns and peer-feedback", Distance Education, Vol. 40 No. 3, pp. 350-379. 
AAOUJ 16,1

Izumi, T., Sukhwani, V., Surjan, A. and Shaw, R. (2020), "Managing and responding to pandemics in higher educational institutions: initial learning from COVID-19", International Journal of Disaster Resilience in the Built Environment, pp. 1-16.

James-Gordon, Y., Young, A. and Bal, J. (2003), "External environmental forces affecting e-learning providers", Marketing Intelligence and Planning, Vol. 21 No. 3, pp. 168-172.

Joanna Rabiega-Wiśniewska (2020), "When students faced online learning in coronavirus times: a case study", The International Virtual Conference on Education, Teaching and Learning, pp. 1-11.

Jones, P., Skinner, H. and Leeds, B. (2014), "Temporal experiences of e-learning by distance learners”, Education + Training, Vol. 56 No. 3, pp. 179-189.

Kufi, E.F., Negassa, T., Melaku, R. and Mergo, R. (2020), "Impact of corona pandemic on educational undertakings and possible breakthrough mechanisms", BizEcons Quarterly, Vol. 11 No. 1, pp. 3-14.

Lall, S. and Singh, N. (2020), "COVID-19: unmasking the new face of education”, International Journal of Research in Pharmaceutical Sciences (SPL), Vol. 11 SPL1, pp. 48-53.

Major, A.E., Chaudhury, S.R., Gilbertson, B.M. and King, D.T. Jr (2014), "An integrated science course moves online: four concurrent perspectives", Journal of Applied Research in Higher Education, Vol. 6 No. 2, pp. 248-268.

Marengo, A. and Marengo, V. (2005), "Measuring the economic benefits of e-learning. a proposal for a new index for academic environments", Joumal of Information Technology Education, Vol. 4 No. 1, pp. 329-346.

McPhee, I. and Söderström, T. (2012), "Distance, online and campus higher education: reflections on learning outcomes", Campus-Wide Information Systems, Vol. 29 No. 3, pp. 144-155.

Moradimokhles, H. and Hwang, G.J. (2020), "The effect of online vs. blended learning in developing English language skills by nursing student: an experimental study", Interactive Learning Environments, Vol. 28, pp. 1-10.

Naidu, S. (2019), "The changing narratives of open, flexible and online learning”, Distance Education, Vol. 40 No. 2, pp. 149-152.

Nguyen, T. (2015), "The effectiveness of online learning: beyond No significant difference and future horizons", MERLOT Journal of Online Learning and Teaching, Vol. 11 No. 2, pp. 309-319.

Parkes, M., Stein, S. and Reading, C. (2014), "Student preparedness for university e-learning environments", The Internet and Higher Education, Vol. 25, pp. 1-10.

Paul, R.C., Swart, W., Zhang, A.M. and MacLeod, K.R. (2015), "Revisiting Zhang's scale of transactional distance: refinement and validation using structural equation modeling", Distance Education, Vol. 36 No.3, pp. 364-382.

Reichheld, F.F. (2003), “The one number you need to grow”, Harvard Business Review, Vol. 81 No. 12, pp. $46-55$.

Roberts, J., Kigotho, M. and Stagg, A. (2018), "Expanding horizons in open and distance learning", Distance Education, Vol. 39 No. 1, pp. 1-3.

Seaborn, K. and Fels, D.I. (2015), "Gamification in theory and action: a survey", International Journal of Human-Computer Studies, Vol. 74, pp. 14-31.

Uhomoibhi, J., Onime, C. and Wang, H. (2019), “A study of developments and applications of mixed reality cubicles and their impact on learning", International Journal of Information and Learning Technology, Vol. 37, pp. 15-31.

UNESCO (2020), COVID-19 Impact on Education, UNESCO, available at: https://en.unesco.org/ covid19/educationresponse.

Upadhayay, L. and Vrat, P. (2017), "Policy boomerang in technical education: a system dynamics perspective", Journal of Advances in Management Research, Vol. 14 No. 2, pp. 143-161.

Veletsianos, G. and Houlden, S. (2019), "An analysis of flexible learning and flexibility over the last 40 years of distance education”, Distance Education, Vol. 40 No. 4, pp. 454-468. 
Wong, B.T.M. (2015), "Pedagogic orientations of MOOC platforms: influence on course delivery", Asian Association of Open Universities Journal, Vol. 10 No. 2, pp. 49-66.

Xiao, J. (2018), "On the margins or at the center? Distance education in higher education", Distance Education, Vol. 39 No. 2, pp. 259-274.

Zhao, Y. (2016), "From deficiency to strength: shifting the mindset about education inequality", Journal of Social Issues, Vol. 72 No. 4, pp. 716-735.
Systematic research of e-learning platforms

\section{Appendix}

The appendix file are available online for this article.

\section{Corresponding author}

Shivangi Viral Thakker can be contacted at: shivangiruparel@somaiya.edu 